\title{
PENGARUH MEDIA AUDIOVISUAL TERHADAP KEMAMPUAN MENULIS TEKS EKSPOSISI PADA SISWA KELAS X SMK SWASTA SULTAN ISKANDAR MUDA TAHUN PELAJARAN 2018/2019
}

\author{
Sumitra $^{1}$, Sri Dinanta Beru Ginting ${ }^{2}$, Udut Silaen ${ }^{3}$ \\ Universitas Prima Indonesia ${ }^{1}$, Universitas Prima Indonesia ${ }^{2}$, Universitas Prima Indonesia ${ }^{3}$ \\ Pos-el: sumitra.scorpio@gmail.com ${ }^{1}$, sridinantaginting@unprimdn.ac.id ${ }^{2}$, \\ udutsilaen@gmail.com ${ }^{3}$
}

\begin{abstract}
ABSTRAK
Tujuan utama yang ingin dicapai dalam penelitian ini adalah untuk mengetahui adakah pengaruh penggunaan media audiovisual terhadap kemampuan menulis teks eksposisi pada siswa kelas X SMK Swasta Sultan Iskandar Muda Tahun Pelajaran 2018/2019. Penelitian ini menggunakan metode kuantitatif Eksperimen dengan desain two group post-test design only. Adapun populasi dalam penelitian ini adalah seluruh siswa kelas X Multimedia SMK Swasta Sultan Iskandar Muda yang berjumlah 66 siswa. Sampel Penelitian terdiri dari dua kelas, satu kelas sebagai kelas kontrol yaitu kelas X-MM 2 sejumlah 32 siswa dan satu kelas sebagai kelompok eksperimen yaitu X-MM 1 sejumlah 34 siswa. Pengambilan sampel ini dengan random sampling (acak kelas ). Teknik pengumpulan data dengan menggunakan tes, yaitu posttest. Proses pengumpulan data dengan cara menugaskan siswa menulis Teks Eksposisi. Sebelum dilakukan analisis data, terlebih dahulu dilakukan uji normalitas dan uji homogenitas yang menunjukkan bahwa skor post-test berdistribusi normal dan homogen. Teknik analisis data adalah uji-t. Hasil penelitian menunjukan adanya perbedaan kemampuan menulis teks ekspsosisi pada siswa kelas X SMK Swasta Sultan Iskandar Muda dengan menggunakan media audiovisual dan tanpa menggunakan media audiovisual. Perbedaan tersebut ditunjukan oleh hasil uji-t yaitu $-\mathrm{t}_{\text {tabel }}=-1,998>\mathrm{t}_{\text {hitung }}=-2,21>\mathrm{t}_{\text {tabel }}=1,998$, maka hipotesis nol $\left(\mathrm{H}_{0}\right)$ ditolak dan Hipotesis alternatif $\left(\mathrm{H}_{\mathrm{a}}\right)$ diterima. Hal ini dibuktikan bahwa terdapat pengaruh positif penggunaan media audiovisual terhadap kemampuan menulis teks eskposisi pada siswa kelas $\mathrm{X}$ Multimedia SMK Swasta Sultan Iskandar Muda Tahun Pelajaran 2018/2019.
\end{abstract}

Kata Kunci: Media Audiovisual, Teks Eksposisi, Eksperimen.

\begin{abstract}
The main objectives to be achieved in this research is to know is there any influence the use of audiovisual media against writing skills text Exposition at grade X SMK Sultan Iskandar Muda Years Private Lessons 2018/2019. These studies use quantitative methods Experimental design with two group post-test design only. As for the population in this research is the whole grade X Multimedia Private SMK Sultan Iskandar Muda of 66 students. The study sample consists of two classes, one class as the class control i.e. class X-2 MM number of 32 students and a class as a group of experiments, namely X-MM 1 a number of 34 students. This sampling with random sampling (random class). Data collection techniques with the use of the test, i.e. post-test. The process of data collection by way of assigning students to write the text of the exposition. Prior to data analysis, first conducted a test of its homogeneity and normality test which showed that score post-test Gaussian and homogeneous. Technique of data analysis is a test-t. Research results showed the existence of a difference ekspsosisi text writing skills in students of class X SMK Sultan Iskandar Muda Private by using audiovisual media and without the use of audiovisual media. The difference is indicated by the test results-t IE-ttabel =-thitung
\end{abstract}


$=-1.998>2.21=$ ttabel $>1.998$, then the zero hypothesis $(H O)$ is rejected and the alternative hypothesis (Ha) received. This is evidenced that there is a positive influence on the use of audiovisual media against writing skills eskposisi text at grade X Multimedia SMK Sultan Iskandar Muda Years Private Lessons 2018/2019.

Keywords: Audiovisual Media, Eksposisi Text, Experiment.

\section{PENDAHULUAN}

Keterampilan menulis dapat digunakan untuk mencatat, merekam, meyakinkan melaporkan, menginformasikan, dan mempengaruhi pembaca. Maksud dan tujuan seperti itu hanya dapat dicapai dengan baik oleh para siswa yang dapat menyusun dan merangkai jalan pikiran serta mengemukakan secara tertulis, lancar dan komunikatif. Tarigan (2013:3) mengatakan "Menulis merupakan suatu kegiatan yang produktif dan ekspresif'.

Morsey dalam Guntur Tarigan (2013: 4) mengatakan "menulis dipergunakan, melaporkan, memberitahukan, mempengaruhi; dan serta tujuan seperti itu hanya dapat dicapai dengan baik oleh orang-orang yang dapat menyusun pikirannya dan mengutarakannya dengan jelas, kejelasan ini bergantung pada pikiran, organisasi, pemakaian kata-kata, dan struktur kalimat"

Dalam pembelajaran Bahasa dan Satra Indonesia terdapat empat aspek keterampilan berbahasa dan sastra. Keempat aspek tersebut adalah keterampilan menyimak, keterampilan berbicara, keterampilan membaca dan keterampilan menulis. Diantara keempat keterampilan tersebut, keterampilan menulis sepertinya perlu mendapat perhatian lebih besar dari pada ketiga aspek keterampilan lainnya. Pembelajaran menulis teks eksposisi harus dilaksanakan secara terstruktur. Artinya siswa harus mengerti dan memahami dengan baik mengenai materi teks eksposisi secara terperinci dan jelas.

Agar dapat menulis teks eksposisi dengan baik dan benar, siswa harus memahami pengertian teks eksposisi, ciri-ciri teks eksposisi, tujuan menulis teks eksposisi, serta langkah-langkah menulis teks eksposisi dengan baik dan benar. Penulis memilih media video sebagai alat bantu untuk menyampaikan materi dan informasi yang akan disampaikan sesuai materi yang ada. Media ini dipilih karena memiliki kelebihan yaitu lebih mudah dimengerti oleh siswa untuk menyampaikan materi. Tentunya, materi menulis teks eksposisi memiliki keterkaitan dengan media video. Keterkaitan antara media video dengan menulis eksposisi yaitu melalui media video yang ditayangkan, siswa dapat menulis teks eksposisi dengan benar.

Berdasarkan latar belakang yang telah di paparkan di atas, penulis tertarik untuk meneliti mengenai pembelajaran menulis teks eksposisi dengan menggunakan media audiovisual (video).

\section{METODE PENELITIAN}

Pendekatan yang digunakan dalam penelitian ini adalah pendekatan kuantitatif. Pendekatan kuantitatif digunakan untuk melihat bagaimana pengaruh media audiovisual terhadap kemampuan menulis teks eksposisi dengan analisis statistik. Dalam suatu penelitian, metode memegang peranan yang sangat penting sebab dalam semua Kegiatan yang akan dilakukan, sebuah penelitian sangat tergantung pada metode yang akan digunakan. Sesuai dengan pendapat Arikunto (2016:22) yang mengatakan "metode penelitian merupakan struktur yang sangat penting, karena berhasil tidaknya, ataupun tinggi rendahnya kualitas hasil penelitian 
sangat di tentukan oleh ketetapan dan memilih metode penelitian".

Adapun metode yang akan digunakan dalam penelitian ini adalah metode eksperimen dengan menggunakan model two group post-test design only. Metode ini digunakan dengan tujuan dapat mengetahui pengaruh teknik melihat langsung dari video yang di tayangkan terhadap kemampuan menulis teks eksposisi pada siswa kelas X SMK Swasta Sultan Iskandar Muda Medan Tahun Pembelajaran 2018/2019.

\section{HASIL DAN PEMBAHASAN}

Tabel Distribusi Data Kemampuan Menulis Teks Eksposisi Siswa di Kelas Kontrol Tanpa Perlakuan

\begin{tabular}{|c|c|c|c|r|c|}
\hline $\begin{array}{c}\text { Selang } \\
\text { Nilai }\end{array}$ & $\mathrm{Fi}$ & $\mathrm{Xi}$ & $\mathrm{FiXi}$ & \multicolumn{1}{c|}{$\mathrm{Xi} 2$} & $\begin{array}{c}\text { Fi(Xi) } \\
2\end{array}$ \\
\hline $45-49$ & 3 & 47 & 141 & 2209 & 6627 \\
\hline $50-54$ & 0 & 0 & 0 & 0 & 0 \\
\hline $55-59$ & 5 & 52 & 260 & 2704 & 13520 \\
\hline $60-64$ & 11 & 57 & 627 & 3249 & 35739 \\
\hline $65-69$ & 7 & 67 & 469 & 4489 & 31423 \\
\hline $70-74$ & 2 & 72 & 144 & 5184 & 10368 \\
\hline $75-79$ & 4 & 77 & 308 & 5929 & 23716 \\
\hline & 32 & 372 & 1949 & 23764 & 3 \\
\hline
\end{tabular}

Berdasarkan tabel di atas dilakukan perhitungan yang dimulai dari menyusun daftar distribusi frekuensi. Namun, sebelum menyusun daftar distribusi frekuensi terlebih dahulu mencari nilai rata-rata dan simpangan baku. Adapun nilai rata-rata kelas kontrol yakni 61,63 standar deviasi kelas kontrol 71,46 dan simpangan baku yaitu 8,53

\section{Tabel Distribusi Data Kemampuan Menulis Teks Eksposisi Kelas Eksperimen dengan Media Audiovisual}

\begin{tabular}{|c|c|c|c|c|c|}
\hline $\begin{array}{c}\text { Selang } \\
\text { Nilai }\end{array}$ & $\mathrm{Fi}$ & $\mathrm{Xi}$ & $\mathrm{FiXi}$ & $\mathrm{Xi} 2$ & $\mathrm{Fi}(\mathrm{Xi}) 2$ \\
\hline $55-60$ & 4 & 57.5 & 230 & 3306.25 & 13225 \\
\hline $61-66$ & 2 & 63.5 & 127 & 4032.25 & 8064.5 \\
\hline
\end{tabular}

\begin{tabular}{|c|c|c|c|c|c|}
$67-72$ & 6 & 69.5 & 417 & 4830.25 & 28981.5 \\
\hline $73-78$ & 8 & 75.5 & 604 & 5700.25 & 45602 \\
\hline $79-84$ & 2 & 81.5 & 163 & 6642.25 & 13284.5 \\
\hline $85-90$ & 12 & 87.5 & 1050 & 7656.25 & 91875 \\
\hline & 34 & 435 & 2591 & 32167.5 & 201033 \\
\hline
\end{tabular}

Berdasarkan tabel di atas dilakukan perhitungan yang dimulai dari menyusun daftar distribusi frekuensi. Namun, sebelum menyusun daftar distribusi frekuensi terlebih dahulu mencari nilai rata-rata dan simpangan baku. Adapun nilai rata-rata kelas eksperimen yakni 76,20 standar deviasi kelas eksperimen 108,57 dan simpangan baku yaitu 10,42

\section{Tabel Uji Normalitas Data dengan Uji} Liliefors

\begin{tabular}{|c|c|c|c|c|c|}
\hline No & Data & Kelas & Lo & Ltabel & $\begin{array}{c}\text { Kesimpu } \\
\text { lan }\end{array}$ \\
\hline 1 & $\begin{array}{c}\text { Poss } \\
\text { test }\end{array}$ & $\begin{array}{c}\text { Kontr } \\
\text { ol }\end{array}$ & $\mathbf{0 , 1 5 7}$ & $\mathbf{0 , 1 6}$ & Normal \\
\hline 2 & $\begin{array}{c}\text { Postt } \\
\text { est }\end{array}$ & $\begin{array}{c}\text { Ekspe } \\
\text { men }\end{array}$ & $\mathbf{0 , 1 3 4}$ & $\mathbf{0 , 1 5}$ & Normal \\
\hline
\end{tabular}

Berdasarkan kriteria pengujian yaitu menerima sampel berasal dari populasi berdistribusi normal jika $\mathrm{L}_{\text {hitung }}$

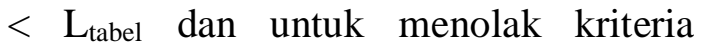
pengujian jika syarat tidak dipenuhi. Berdasarkan tabel harga $\mathrm{L}_{\text {hitung }}<\mathrm{L}_{\text {tabel }}$ ini berarti menerima kriteria.

Tabel Uji Homogenitas

\begin{tabular}{|c|c|c|c|c|}
\hline Data & Varians & $\mathbf{F}_{\text {hitung }}$ & $\mathbf{F}_{\text {tabel }}$ & $\begin{array}{c}\text { Kesim } \\
\text { pulan }\end{array}$ \\
\hline $\begin{array}{c}\text { Posttest } \\
\text { Kontrol }\end{array}$ & $\mathbf{7 1 , 4 6}$ & \multirow{2}{*}{1,25} & 1,81 & $\begin{array}{c}\text { Homo } \\
\text { gen }\end{array}$ \\
\cline { 1 - 2 } $\begin{array}{c}\text { Posttest } \\
\text { Eksperi } \\
\text { men }\end{array}$ & $\mathbf{1 0 8 , 5 7}$ & & \\
\hline
\end{tabular}

Berdasarkan tabel di atas data posttest untuk kedua sampel diperoleh $\mathrm{F}_{\text {hitung }}<\mathrm{F}_{\text {tabel }}$ maka diterima $\mathrm{H}_{0}$ bahwa sampel memiliki varians yang homogen. Jika sebaliknya maka, varians tidak homogen. 
Tabel Uji Hipotesis

\begin{tabular}{|c|c|c|c|c|}
\hline Data & $\begin{array}{l}\text { Nilai } \\
\text { rata- } \\
\text { rata }\end{array}$ & $\mathbf{t}_{\text {hitung }}$ & $\mathbf{t}_{\text {tabel }}$ & $\begin{array}{c}\text { Kesim } \\
\text { pulan }\end{array}$ \\
\hline $\begin{array}{l}\text { Posttest } \\
\text { Kontrol }\end{array}$ & 61,63 & & & $\begin{array}{c}\text { Ada } \\
\text { pengar }\end{array}$ \\
\hline $\begin{array}{c}\text { Posttest } \\
\text { Eksperi } \\
\text { men }\end{array}$ & 76,20 & 2,21 & 1,998 & $\begin{array}{c}\text { uh } \\
\text { yang } \\
\text { signifi } \\
\text { kan }\end{array}$ \\
\hline
\end{tabular}

Berdasarkan data hasil peneltian kelas kontrol dan eksperimen diperoleh nilai rata-rata kelas kontrol 61,63 dan kelas eksperimen diperoleh nilai ratarata 76,20. Berdasarkan data hasil perhitungan diperoleh $t_{\text {hitung }}=-2,21 \mathrm{t}_{\text {tabel }}$ $=1,998$ maka, kriteria pengujian hipotesis penelitian ini adalah $t_{\text {hitung }}>$ $\mathrm{t}_{\text {tabel,. }}$ Hipotesis nilai $\mathrm{H}_{0}$ ditolak dan hipotesis alternative $\left(\mathrm{H}_{\mathrm{a}}\right)$ diterima. Hal ini membuktikan bahwa terdapat perbedaan yang signifikan antara kelas kontrol dan kelas eksperimen..

\section{SIMPULAN}

Berdasarkan analisis data data uji statistik ditetapkan kesimpulan sebagai berikut:

1. Kemampuan menulis teks eksposisi dengan menggunakan teknik ceramah diperoleh mean (rata-rata) 60,91 termasuk dalam kategori cukup (C). Dapat diketahui bahwa kemapuan menulis teks eksposisi siswa termasuk kategori sangat baik sebanyak 0 siswa atau $0 \%$, baik sebanyak 4 siswa atau $12,50 \%$, kategori cukup sebanya 9 atau $28,10 \%$, kategori kurang sebanyak 16 siswa atau $50 \%$, kategori sangat kurang sebanyak 3 siswa atau 9,4\%.

2. Kemampuan menulis teks eksposisi dengan menggunakan media audiovisual diperoleh mean (rata-rata) 76,20 termasuk dalam kategori baik (B). Dapat diketahui bahwa menulis teks eksposisi siswa termasuk kategori sangat baik sebanyak 12 siswa atau $35,29 \%$, kategori baik sebanyak 10 siswa atau 29,41\%, kategori cukup sebanyak 8 siswa atau 23,54\%, kategori kurang sebanyak 8 siswa atau $23,54 \%$, dan kategori sangat kurang sebanyak 0 siswa atau $0 \%$.

3. Berdasarkan perhitungan yang telah dilakukan. Maka dapat diketahui bahwa thitung $>t_{\text {tabel }}$ yakni 2,21>1,998 Dengan demikian hipotesis nihil $\left(\mathrm{H}_{\mathrm{o}}\right)$ ditolak dan hipotesis alternative $\left(\mathrm{H}_{\mathrm{a}}\right)$ diterima. Sehingga dapat disimpulkan bahwa teknik media audiovisual memiliki pengaruh terhadap kemampuan menulis teks eksposisi pada siswa kelas X SMK Sultan Iskandar Muda Tahun Pembelajaran 2018/2019.

Berdasarkan kesimpulan diatas, maka sebagai tindak lanjut penelitian ini perlu diungkapkan beberapa saran dalam bagaian dibawah ini.

1. Kemampuan siswa menulis teks eksposisi perlu ditingkatkan lagi. Hal tersebut tentunya memerlukan model pembelajaran yang lebih efektifdigunakan dalam proses belajar mengajar (PBM) disekolah. Salah satu teknik mengajar yang dapat dijadikan alternative adalah teknik dengan nggunakan media audiouvisual.

2. Untuk menggunakan teknik media audiovisual ini diperlukan pemahaman guru bahsa dan sastra Indonesia baik dari segi persiapan, pelaksanaan, sampai evaluasi agar hal yang diharapkan yakni peningkatan kemampuan menulis teks eksposisi siswa dapat lebih baik.

3. Disarankan agar peneliti selanjutnya tetap memperhatikan perkembangan model-model pembelajaran atau stategi-strategi pewmbelajaran yang digunakan dalam sekolah khususnya dalam pembelajaran menuli teks eksposisi. 
4. Kepada kepala sekolah SMK Sultan Iskandar Muda, agar mengupayakan pengadaan bukubuku yang menyangkut tentang pembelajaran bahasa Indonesia, khusunya teknik-teknik dalam nemulis teks eksposisi serta kaitan dengan teknik pembelajaran.

\section{DAFTAR PUSTAKA}

Arikunto. 2016. Prosedur Penelitian Suatu Pendekatan praktek. Jakarta: Rineke Cipta.

Ali \& Asori. 2014. Metodologi \& Aplikasi Riset Pendidikan.Jakarta:PT.Bumi Aksara

Dalman. 2015. Keterampilan Menulis. Jakarta: PT Raja Grafindo Persada.

Dimyati \& Mudjiono. 2013. Belajar \& Pembelajaran. Jakarta: Rineka Cipta.

Hamdani. 2017. Strategi Belajar Mengajar. Bandung: Pustaka Setia.

Keraf, Goris. 2017. Eksposisi. Jakarta: PT Grasindo.

Kosasih. 2017. Jenis-Jenis Teks. Bandung: Yrama Widya Margahayu Permai.

Kosasih. 2011. Ketatabahasaan dan Kesusastraan. Bandung: CV. Yrama widya.

Karo-karo, Nalsaria. 2014. "Pengaruh Media Audiovisual Terhadap Kemampuan Menulis Teks Berita Siswa Kelas X SMA Global Prima Medan". Skripsi: Fakultas Keguruan dan Ilmu Pendidikan.

Ngalimun. 2017. Konsep Dasar Keterampilan Menulis. Yogyakarta:Parama Ilmu

Pujiono, Setyawan. 2013. Terampil Menulis. Yogyakarta: Graha Ilmu.

Sugiyono. 2017. Metode Penelitian Pendidikan. Bandung: Alfabeta.
Sudjana. 2005. Metoda Statistika. Bandung: Tarsito.

Semi. 2017. Dasar-dasar Keterampilan Menulis. Bandung: Angkasa.

Sinaga, Rosita Luxerida. 2011. "Pengaruh Teknik Kunjungan Lapangan Terhadap Kemampuan Menulis Paragraf Deskripsi Siswa Kelas X SMA Negeri 1 Silou Kahean". Skripsi: Fakultas Keguruan dan Ilmu Pendidikan.

Tarigan, Henry Guntur. 2008. Menulis Sebagai Suatu Kemampuan Berbahasa. Bandung: Angkasa.

Wati, Ega Rima. 2016. Ragam Media Pembelajaran. Yogyakarta: Kata pena. 